\title{
Methods for the recombinant expression of active tyrosine kinase domains: guidelines and pitfalls
}

\author{
Authors: M.Escarlet Díaz Galicia, Abdullah Aldehaiman, SeungBeom Hong, Stefan T. \\ Arold*, Raik Grünberg*
}

Author information:

King Abdullah University of Science and Technology (KAUST), Computational Bioscience Research Center (CBRC), Division of Biological and Environmental Sciences and Engineering (BESE), Thuwal 23955-6900, Saudi Arabia

*Correspondence can be addressed to : STA (stefan.arold@kaust.edu.sa) or RG

(raik.grunberg@kaust.edu.sa)

\begin{abstract}
Protein tyrosine kinases (PTKs) are key signaling molecules and important drug targets. Although the efficient recombinant production of active PTKs is important for both pharmaceutical industry and academic research, most PTKs are still obtained from conventional, expensive and time-consuming insect-cell based expression. Host toxicity, kinase inactivity, insolubility and heterogeneity are among the reasons thought to preclude PTK expression in Escherichia coli. Herein we review these presumed roadblocks and their possible solutions for bacterial expression of PTKs, and give an overview on kinase activity assays. Finally, we report our experiences and observations with the kinases Src, Lyn and FAK as examples to illustrate implementation, effects and pitfalls of E. coli expression and in vitro assaying of PTKs.
\end{abstract}

Key words: protein tyrosine kinase, Lyn, FAK, Src, kinase activity, kinase recombinant expression. 


\section{Content}
Abstract
1. Introduction
2. Expression of PTKs in eukaryotic systems
3. PTK expression from $E$. coli.
4. In-vitro kinase activity assays
5. Practical guidelines and hidden-pitfalls
Expression vectors
Expression screen
Influence of phosphatase co-expression
PTP1B co-expression and kinase assays

\section{Conclusion}

Experimental procedures

Acknowledgements

\section{References}

\section{Figures}




\section{Introduction}

Kinase-mediated phosphorylation of serine, threonine or tyrosine side chains rapidly and reversibly alters protein function, conformation and interaction partners. In particular, this mechanism is widely used in metazoans where a large part of the proteome experiences some type of phosphorylation (Sharma et al., 2014). Within the eukaryotic protein kinase family, protein tyrosine kinases (PTKs) appear to be the most recent addition to the cell's signaling repertoire. (Herein, we distinguish between 'PTKs', which can have additional non-kinase domains on the same polypeptide chain, and 'kinase domains' (KDs), which refer to the catalytic domain of any type of kinase). In fact, tyrosine phosphorylation was suggested to have opened a new biochemical "communication channel" which may have been a prerequisite for the development of multicellularity (Lim \& Pawson, 2010; Hunter, 2009). This view is supported by the role of eukaryotic PTKs as important regulators of processes closely linked to multicellular organization in addition to proliferation, hormone response and immune reactions (Hunter, 2009). In contrast to serine or threonine phosphorylation, human cells tightly down-regulate phosphorylation on tyrosines. In the absence of specific signaling events, most tyrosine phosphorylation sites remain "switched off" (Sharma et al., 2014). This is also reflected in the human genome, where protein tyrosine phosphatases (PTPs) outnumber PTKs 107 to 90 (Alonso et al., 2004). By contrast, the 428 serine / threonine kinases are countered by only 28 serine / threonine phosphatases (Sacco, Perfetto, Castagnoli, \& Cesareni, 2012).

Multiple human health threats such as cancer or diabetes, as well as immune, neurological, infectious and inflammatory diseases have been associated with the dysregulation of protein kinases (Bhullar et al., 2018; Patterson, Nibbs, McInnes, \& Siebert, 2014). The targeted inhibition of PTKs is therefore of high therapeutic and pharmaceutical interest, which has spurred the quest to understand the structure, specificity and control of PTKs. In 2018 alone, seven thousand publications report on kinase inhibitors (PubMed), in addition to undisclosed research within the pharmaceutical industry. To date, the US Food and Drug Administration (FDA) has approved 37 kinase inhibitors to treat cancer and 150 similar drugs are currently in clinical trials (Bhullar et al., 2018). Imatinib and Dasatinib are the best-known examples and have advanced the treatment of myeloid leukemia (for reviews, see (Wu, Nielsen, \& Clausen, 
2016; Fountas, Diamantopoulos, \& Tsatsoulis, 2015; Agafonov, Wilson, Otten, Buosi, \& Kern, 2014)).

Aside from the therapeutic interest in KDs, their modularity, compatibility with other signaling systems and their capacity to function as "protein interaction computation nodes" make them a promising building block for the engineering of synthetic protein systems. In native proteins, KDs are often found fused to other domains, which can direct the kinase to specific targets or regulate its enzymatic activity. In fact, the very concept of a modular protein domain arose from the study of the oncogenic Src kinase, which remains a model PTK to this day (Pawson, 1995). The artificial rewiring of the PTK's domain composition can redirect signaling flows and could pave the way to designed protein circuits with applications in vitro or in living cells (Gordley, Bugaj, \& Lim, 2016; Grünberg \& Serrano, 2010). Moreover, recently described "split kinase" systems may offer an engineering shortcut through the complex regulation of kinase activity (Diaz et al., 2017; Camacho-Soto, Castillo-Montoya, Tye, \& Ghosh, 2014; Y. Ma, Nagamune, \& Kawahara, 2014).

Fundamental research, drug design, synthetic biology and biotechnology all depend heavily on the availability of pure, soluble and active PTKs. The fastest and cheapest expression system is E. coli. However, while many serine/threonine kinases can be expressed easily in bacteria, PTKs are considered more challenging expression targets. This difficulty is somewhat surprising as PTKs and serine/threonine kinases are structurally highly similar (Figure 1A). Consequently, most PTKs are currently expressed from insect or mammalian cells. However, these methods are expensive and slow, hampering the rapid generation of mutants and new constructs as required for the trial-and-error workflow of bioengineering projects and mechanistic studies.

Herein, we briefly review PTK expression protocols from insect and mammalian cells. Given the marked advantages of $E$. coli-based protein expression methods, we will discuss the reasons that impede production of active PTKs in E. coli, and review possible solutions. Additionally, we will use our own experiences with the PTKs FAK, Src and Lyn (Figure 1B) to highlight some of the pitfalls and oddities associated with the expression of PTKs. Finally, given that the ability to measure and quantify kinase activity is instrumental to evaluating the success of recombinant kinase production, we also review kinase activity assays. 

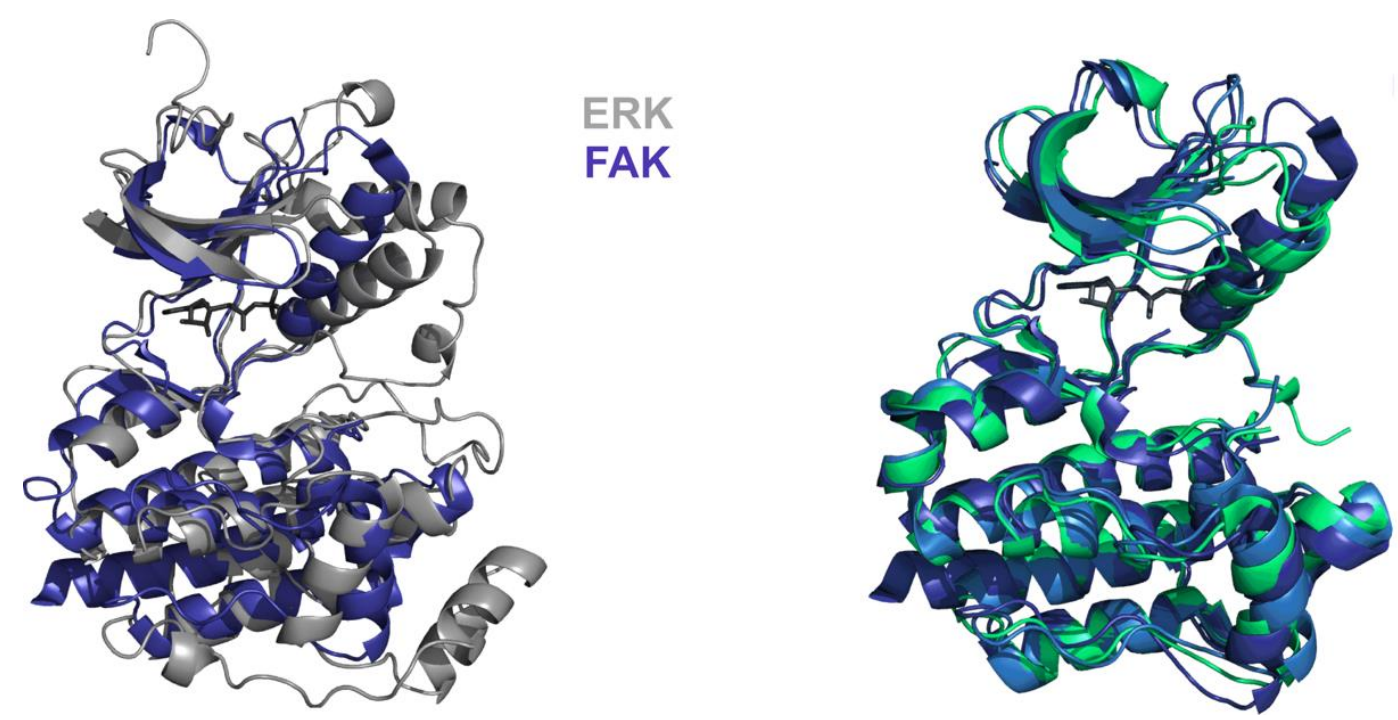

Figure 1. Structural comparison of the catalytic domains of ERK, Src, Lyn and FAK. A) Backbone superposition of serine kinase ERK2 (Grey) and tyrosine kinase FAK (Red), root mean square difference $(\mathrm{RMSD})=1.07 \AA$. B) Superposition of tyrosine kinases Lyn (Blue), FAK (Purple), and Src (Green) catalytic domains, RMSD = $1.70 \AA$ A. In both figures, bound ADP is shown as stick model.

\section{Expression of PTKs in eukaryotic systems}

In initial studies on the topic, PTKs appeared difficult to express in E. coli and were generally cytotoxic to yeast. In particular for structural studies, requiring large amounts of pure protein, insect cell expression quickly emerged as the method of choice. The baculovirus-insect cell system has long been a strong workhorse for the expression of eukaryotic recombinant proteins that are not well-expressed, folded and/or processed in E. coli (van Oers, Pijlman, \& Vlak, 2015; Smith, Summers, \& Fraser, 1983). In the most common workflow, the target gene(s) are first cloned between $\operatorname{Tn} 7$ transposon sites into a bacterial donor plasmid (i.e. pFASTBAC). This puts them under the control of either the polyhedrin or the P10 promoters which are derived from the Autographa californica multiple nucleopolyhedrovirus (AcMNPB). The expression cassette is then transferred by transposon-mediated insertion into a Bacmid shuttle vector that can be propagated in both $E$. coli and insect cells and encodes all the remaining components of the virus. Actual virus is produced after transfection of this Bacmid into Spodoptera frugiperda (fall armyworm) insect cells and then used to infect a larger production culture of the same cell type (Pijlman, van Schijndel, \& Vlak, 2003; Luckow, Lee, Barry, \& Olins, 1993). With this system, many eukaryotic kinases have been successfully expressed and purified to high yields of active protein. We have deposited a detailed example protocol for 
insect-cell production of multidomain constructs of the PTKs Src and FAK along with the resulting kinase activities at https://github.com/strubelab/kinaseexpress. Nevertheless, insect cell expression requires a minimum of three to four weeks from an initial cloning of the target gene into the bacterial vector to the actual protein expression. Furthermore, when compared to the $E$. coli expression system, growth media and the additional infrastructure required, the maintenance of insect cell cultures is relatively expensive.

Nonetheless, insect cell expression still compares very favorably to traditional methods for the large-scale expression from mammalian cell lines. Although production from mammalian cells allows native post-translational modifications and chaperon-assisted folding of human proteins (Nettleship, Assenberg, Diprose, Rahman-Huq, \& Owens, 2010; Bruel, Cha, Reeves, Getmanova, \& Khorana, 2000), the time and resources involved are often only invested in an industrial setting. For example, more than half of biopharmaceutical (therapeutic) proteins are currently produced from mammalian cell culture (Khan, 2013). In an academic context, mammalian production of PTKs seems mostly limited to small-scale expression from transiently transfected cells (Deng et al., 2014). Nevertheless, recent lentiviral transfection protocols (Elegheert et al., 2018) or baculovirus-mediated gene transfer into mammalian cells (BacMam) (Goehring et al., 2014; Hofmann et al., 1995) obviate the generation of stable cell lines and shorten the mammalian expression protocol to a time frame that is comparable with insect cell expression. This method is thus also becoming attractive for the large-scale expression of PTKs.

\section{PTK expression from $E$. coli}

About $60 \%$ of all recombinant proteins mentioned in the literature (Correa \& Oppezzo, 2015) and close to $90 \%$ of proteins with known structure (Nettleship et al., 2010) have been produced in E. coli. Indeed, where applicable, E. coli typically provides the easiest, fastest and cheapest access to larger quantities of recombinant protein. But not all proteins can be produced in this system. Eukaryotic proteins in particular are often subject to degradation or aggregation in inclusion bodies (Correa \& Oppezzo, 2015; Rosano \& Ceccarelli, 2014). In a direct comparison of 62 full-length human kinases, all but one showed soluble expression from insect cells compared to only a $54 \%$ overall success rate for expression in E. coli. Among the six major groups of kinases tested, PTKs performed the worst with less than 30\% success (Chambers, Austen, Fulghum, \& Kim, 2004). However, this result may have been biased by the use of 
sequences with the original mammalian codon usage in an expression vector that was optimized for insect-cell expression. By contrast, thanks also to a targeted structural genomics effort, the PDB now contains many human kinase structures, including also PTKs, that were produced from E. coli-expressed proteins (SGC, 2013). Starting from this record of successful expression in E. coli, Albanese et al. assembled a panel of $96 \mathrm{KD}$ expression constructs, spanning 8 kinase families. Small-scale expression together with a phosphatase (but without any further optimization) succeeded for 10 out of the 17 tyrosine KDs tested, which compares well with the overall success rate of $56 \%$ (Albanese et al., 2018).

Also the earliest attempts of purifying mammalian c-Src KD from E. coli did not fail outright but reported low yields of soluble protein (Osusky, Taylor, \& Shalloway, 1995; Saya et al., 1993). Meanwhile, expression attempts in yeast indicated a general cytotoxicity of PTKs in this system, although, in the case of c-Src, this cytotoxicity could be overcome by the coexpression of human PTP-PEST as an antagonizing phosphatase (Weijland et al., 1996). In $E$. coli, the picture was less clear. Sufficient expression and activity was, for example, shown for v-Abl (Garcia et al., 1993), for Csk (Bougeret, Rothhut, Jullien, Fischer, \& Benarous, 1993) (each fused to GST) and later also claimed for the expression of c-Src, c-Abl, and c-Met KDs (W. Wang et al., 2006). In the meantime, co-expression of an antagonizing phosphatase was reported to improve kinase yields also in the E. coli expression system (W. Wang et al., 2006; Seeliger et al., 2005). Two different phosphatases, YopH and PTP1B, were introduced for this purpose: YopH is an unspecific tyrosine phosphatase derived from the bacterial pathogen Yersinia (Bliska, Guan, Dixon, \& Falkow, 1991) and was employed to produce recombinant cSrc and c-Abl KDs (Seeliger et al., 2005). PTP1B had earlier been identified as the primary human phosphatase targeting and activating c-Src (Bjorge, Pang, \& Fujita, 2000) and other PTKs (Fan, Lin, Lucito, \& Tonks, 2013) and was used to improve yield and homogeneity of recombinant c-Src, c-Abl and c-Met KDs (W. Wang et al., 2006). Phosphatase co-expression was then reported in subsequent studies using either PTP1B (Cui \& Sun, 2018; Tu, Wang, Cai, Zhou, \& Zhang, 2014; Y.-H. Wang, Ayrapetov, Lin, \& Sun, 2006) or YopH (Albanese et al., 2018; Wilson et al., 2015; Filippakopoulos et al., 2008). With one dissenting opinion (W. Wang et al., 2006), there seems to be a consensus that the active Src KD is cytotoxic to E. coli and that its recombinant expression benefits from phosphatase co-expression. This conclusion was reinforced by Kemble et al. who showed that different mutants of the Src KD could be expressed in E. coli as long as their enzymatic activity remained below a certain threshold (Kemble, Wang, \& Sun, 2006). However, the view that PTKs are generally cytotoxic to E. coli 
is not backed up by the literature record. Indeed, in contrast to earlier assumptions, E. coli has its own tyrosine phosphorylation and dephosphorylation system (Vincent et al., 1999). Hence, cytotoxicity of PTKs might be related to both their particular intrinsic activity and substrate specificity as well as their level of overexpression.

Aside from potential cytotoxicity, bacterially expressed PTKs seem particularly prone to misfolding and accumulation in inclusion bodies (Piserchio, Cowburn, \& Ghose, 2012; Seeliger et al., 2005; Chambers et al., 2004). Purification of active Src KD from such inclusion bodies was reported (Marin et al., 2010; Gong et al., 2006), but this approach might not be generally applicable. Fusion to solubility-enhancing tags (Kimple, Brill, \& Pasker, 2013) such as GST (Gong et al., 2006; Bougeret et al., 1993; Garcia et al., 1993) or MBP (Piserchio et al., 2012) may increase the soluble fraction. Nevertheless, Piserchio et al. warn that large amounts of soluble MBP-Src fusion product were, in fact, soluble aggregates of still unfolded protein, a problem that they addressed through the co-over-expression of chaperons.

This overexpression of bacterial chaperons has earlier been touted as a general strategy for improved protein production in E. coli (Thomas, Ayling, \& Baneyx, 1997) and was also used by Kemble et al. for the expression of an inactivated c-Src KD (Kemble et al., 2006). In a more systematic comparison, Haake et al. subjected a set of 10 KDs (including 4 non-receptor PTKs, 4 receptor PTKs, and 2 Ser/Thr kinases) to expression with and without different mixtures of bacterial chaperons (Haacke, Fendrich, Ramage, \& Geiser, 2009). Overexpression of chaperons generally reduced the amount of insoluble protein (inclusion bodies), but only increased the yield of affinity-captured soluble protein in about half of the tested KDs. c-Src and Hck KDs (which were also co-expressed with PTP1B) did not benefit from chaperon coexpression. However, also in most of the remaining cases, the formation of soluble aggregates [as assessed by size exclusion chromatography (SEC)] negated the advantage of bacterial chaperon co-expression which, therefore, does not seem to be of general help for PTK expression.

The efficiency of chaperon co-expression might also depend on the choice of chaperones used. Most studies use bacterial chaperones (i.e. GroEL, GroES, DnaK, DnaJ, others) (Piserchio et al., 2012; Haacke et al., 2009; Kemble et al., 2006). However, in their native eukaryotic cell, the folding of many PTKs depends on HSP90 and the kinase-specific co-chaperon CDC37. The two chaperons form a specific complex that preserves the client kinase in an inactive state and protects buried tyrosines from phosphorylation (Verba et al., 2016; Taipale et al., 2012). 
Co-expression of CDC37 alone seems to be beneficial for the expression of active and soluble c-Src KD in E. coli (Piserchio et al., 2012). Further studies are needed to clarify the utility of human chaperon co-expression for PTK production in this host.

Beyond the lack of chaperons, misfolding could also be caused by the kinase itself. Shrestha et al. (2012) analyzed phosphorylation patterns of several Ser/Thr kinases produced in E. coli and suggested that the KDs expressed first "hyper-phosphorylate" subsequently produced kinase molecules while these are still in process of translation and elongation (Shrestha, Hamilton, O’Neill, Knapp, \& Elkins, 2012). Non-native phosphorylation of normally buried residues would likely impair folding and solubility and can also affect the functioning of affinity tags (Du et al., 2005). The prevention of such "hyper-phosphorylation" provides an additional rational for the co-expression of phosphatases during PTK production from E. coli. Hyperautophosphorylation may, in fact, be a more severe problem for tyrosine kinases than for Ser/Thr kinases: Whereas Ser/Thr phosphorylation (and de-phosphorylation) is relatively wide-spread in both eukaryotic and bacterial cells, tyrosine phosphorylation is efficiently and globally suppressed in eukaryotic cells (Sharma et al., 2014). Overexpression in E. coli therefore exposes PTKs to their own uncontrolled high activity, which they have not evolved to cope with.

In summary, although PTKs and their isolated KDs can be difficult targets for expression in $E$. coli, the use of antagonistic phosphatases, optimized domain boundaries and, possibly, also chaperones or solubility tags often enables bacterial production. The proper validation of the expression system requires kinase activity assays, which we will discuss in the next section.

\section{In-vitro kinase activity assays}

The importance of tyrosine kinases as pharmaceutical targets (Breen \& Soellner, 2015) has spurred the development of in vitro activity assays. Principles, advantages and disadvantages of such assays have been previously reviewed (Lorenz, 2011; Glickman, 2004; Hawes \& Biesen, 1999) and we here only give a brief overview and update.

Traditional methods measure tyrosine phosphorylation through the combination of radiolabeling with $\mathrm{AT}^{32} \mathrm{P}$ or $\mathrm{AT}^{33} \mathrm{P}$, immunoprecipitation and western blotting. This strategy has been used to study tyrosine kinase activity for more than two decades with several protocol improvements made during these years (Karra, Stippec, \& Cobb, 2017; Beeler, LaRochelle, 
Chedid, Tronick, \& Aaronson, 1994; Saya et al., 1993). In a recent example of this approach, Marholz et al. enabled assessing the catalytic activity of orphan PTKs (i.e. PTKs for which the substrates are unknown) by the identification of a set of "universal" substrate sequences (Marholz, Zeringo, Lou, Turk, \& Parker, 2018).

Radiolabeling, however, has drawbacks in terms of safety, risks to the environment and the logistics and cost of radioactive transport and waste disposal (Glickman, 2004). A common alternative is the immunoprecipitation with antibodies that either nonspecifically pull-down phosphorylated proteins from cell lysates, or specifically recognize certain phosphorylated target peptides (Amanchy et al., 2009; Hawes \& Biesen, 1999). This method reliably identifies natural kinase substrates in cell samples. However, despite efforts to streamline the collection of quantitative temporal data (Bankston, Ku, \& Feng, 2017; Mazet et al., 2015), this method is still limited in throughput and less amenable to accurate quantification.

Measurement kits from several commercial providers promise to address the shortcomings of traditional methods. Many use antibody detection of phosphorylated substrates followed by fluorescence or luminescence readouts (Altıntop et al., 2018; Gopinathan et al., 2018). PamChip, for example, employs a multiplex ELISA-like strategy in which a library of substrates is attached to a membrane and, following the kinase reaction, is exposed to a fluorescently labelled antibody (Dussaq, Anderson, Willey, \& Almeida, 2016). This approach was used to measure kinase activity in cell lysates (Gopinathan et al., 2018), and as a diagnostic approach for the analysis of kinase inhibitor therapies in patient-derived cell lysates (Arni et al., 2017; Labots et al., 2016). By contrast, the LanthaScreen, another commercially available assay, operates in solution (Carazo \& Pávek, 2015). LanthaScreen assays measure the fluorescence energy transfer (FRET) from a phospho-tyrosine antibody labelled with a donor fluorophore to the acceptor fluorescent dye that is conjugated to a substrate peptide. The method uses the exceptionally long fluorescence life time of lanthanide ions (europium or terbium), which allows to delay the measurement of donor and acceptor emission until background fluorescence from other potentially interfering compounds has decayed (Sumaoka, Akiba, \& Komiyama, 2016; Carlson, Robers, Vogel, \& Machleidt, 2009).

There are also several assays that do not rely on expensive and fragile phosphopeptide antibodies. The ADPGlo assay measures kinase activity indirectly, through the generation of ADP. At the end of the chosen kinase reaction time, any remaining ATP is hydrolyzed to AMP. Kinase-generated ADP is converted back to ATP which is then driving a luciferase reaction 
and quantified by luminescence. This method has, for example, been employed for the characterization of recombinant ribosomal S6 kinase 2 (RSK2) and Tousled-like kinase 1B (Bhoir, Shaik, Thiruvenkatam, \& Kirubakaran, 2018; Utepbergenov et al., 2016). In addition, there exist several variants of non-antibody FRET assays (Liu et al., 2010; Lawrence \& Wang, 2007; Newman \& Josiah, 2004). Z'Lyte for example, quantifies the activity of various kinases with kinase-specific peptides that are labelled with both donor and acceptor fluorophores. After the kinase reaction, only non-phosphorylated peptides are cleaved by a protease, thus separating donor and acceptor fluorophores (Figure 2). The proportion of uncleaved (phosphorylated) versus cleaved (unphosphorylated) peptide is then determined from the ratiometric FRET signal (H. Ma, Deacon, \& Horiuchi, 2008; Rodems et al., 2002).

Thus, depending on her specific needs, a researcher can now choose from a variety of commercial or non-commercial kinase assays to assess catalytic activity of recombinant PTKs.

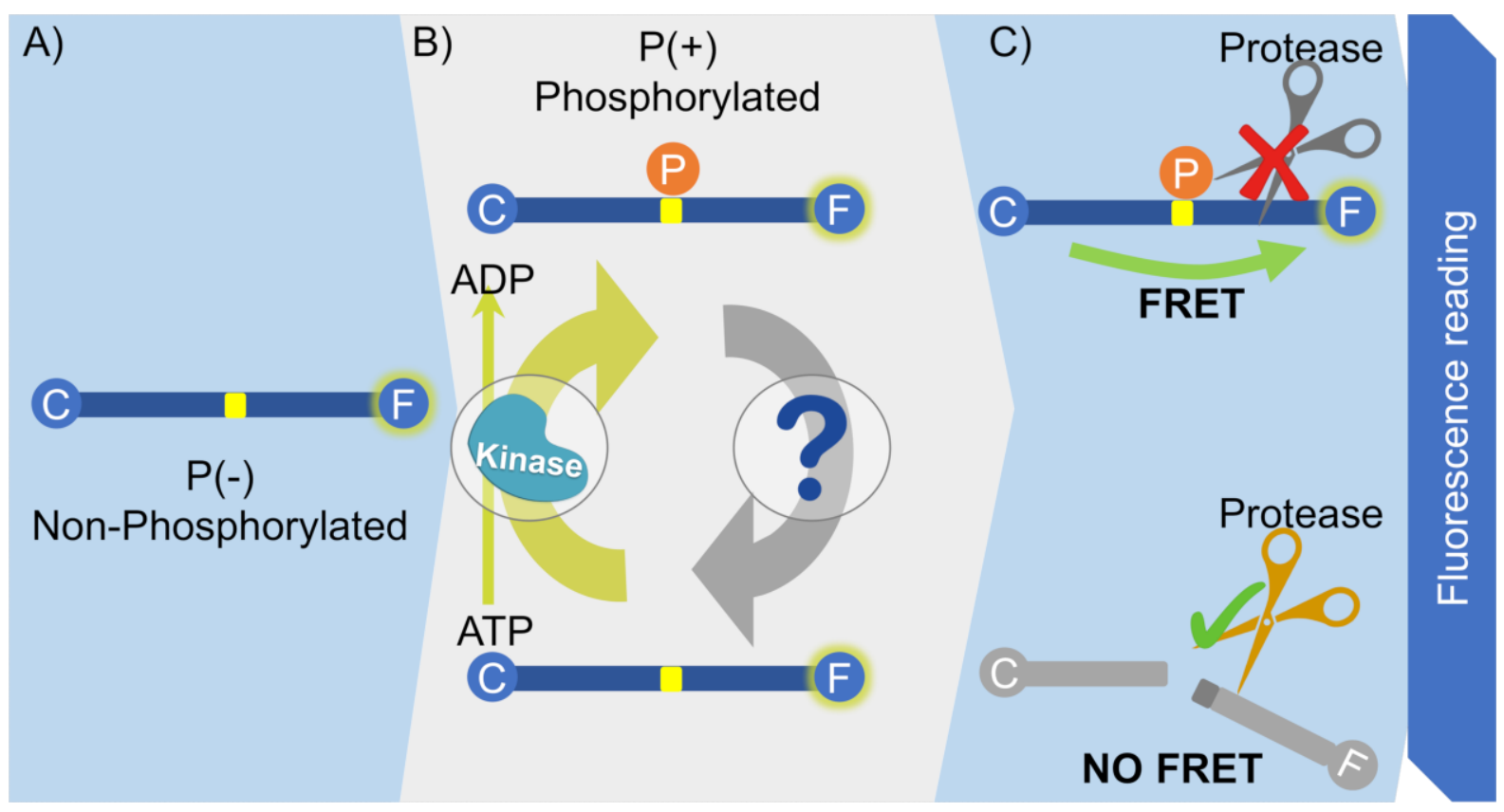

Figure 2. Mechanism of Z'LYTE kinase activity assay.

A) Specific substrate peptides are labeled with FRET donor (coumarin) and acceptor (fluorescein) fluorophores. B) Phosphorylation reaction in the presence of ATP. C) A protease cleaves only non-phosphorylated substrate peptide which leads to an increase in donor and decrease in acceptor fluorescence signal.

\section{Practical guidelines and hidden pitfalls.}

In the following, we will share our experiences with bacterial PTK expression and activity assays, illustrated by experiments with the KDs of three PTKs [Lyn (residues 211-512), FAK 
(residues 374-708 taken from an isoform used by (Camacho-Soto et al., 2014) and Src (residues 234-536)]. Complete sequences and detailed experimental protocols are available at https://github.com/strubelab/kinaseexpress.

\section{Expression vectors}

We codon-optimized PTK KD sequences, considering both E. coli codon and codon-pair usage, optimal GC content, enrichment of hidden stop codons and avoidance of sequence repetitions (J. X. Chin, Chung, \& Lee, 2014). The synthesized genes were recombined into a synthetic protein expression vector (pJExpress411, originally from DNA 2.0, CA) which we had previously modified to include a RBS secondary structure insulation cassette from (Mutalik et al., 2013). In our hands, the combination of codon optimization with 5' mRNA secondary structure suppression very often gives a marked increase in protein expression yields. However, it did not clearly improve PTK KD yields over values reported in the literature (i.e. $22 \mu \mathrm{g} / \mathrm{mL}$ of Src by Albanese et al. or 5-15 mg/L of Src by Seeliger et al.) (Albanese et al., 2018; Seeliger et al., 2005). In all constructs, the catalytic KD was fused to yellow fluorescent mCitrine (Griesbeck, Baird, Campbell, Zacharias, \& Tsien, 2001) followed by a modified TwinStrep purification tag (Schmidt et al., 2013) (Figure 3). The YopH catalytic domain (residues 164468) was expressed from a low copy vector with Spectinomycin resistance (Addgene \#79749) (Albanese et al., 2018), whereas the human PTP1B (fused to GST) was expressed from a high copy plasmid with ampicillin resistance (Addgene \#8602).

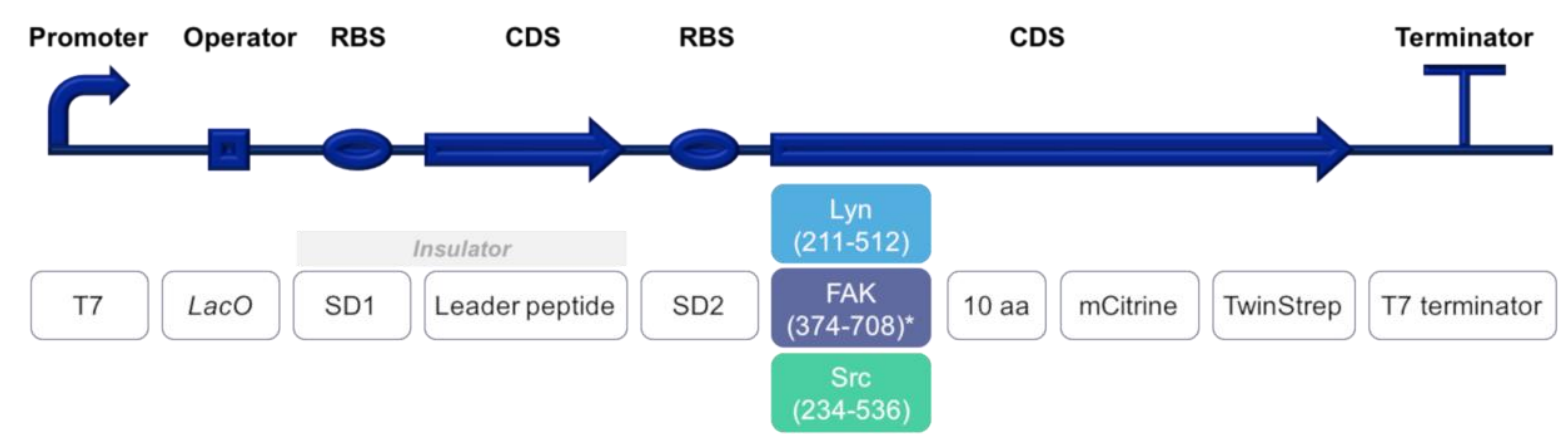

Figure 3. Construct design for kinases expressed in $\boldsymbol{E}$. coli. *: residues 374-708 correspond to residues 2-336 of genbank AAH28733.1. 
Expression screen

We performed a small-scale (4 ml cultures) expression screen that varied incubation temperature and induction strength for three colonies of each kinase construct. Each KD was co-expressed (i) with YopH, (ii) with PTP1B or (iii) expressed alone. After lysis, approximate expression yields were quantified by fluorescence and normalized to cell density (Figure 4). Quantification through fluorescent tags is fast and convenient as it does not require purification or SDS page gels. In our examples, Src KD showed approximately half the fluorescence of Lyn KD under most small-scale conditions and this result was reproduced in the large-scale affinity purification (Figure 4; Table 1A). Yet, this detection method can be deceiving: based on fluorescence, we observed up to ten times higher expression levels for the FAK KD than for Src. However, SDS-PAGE analysis (Supplementary figure S1) revealed that the fluorescence stemmed from truncation products containing mainly the C-terminal mCitrine.
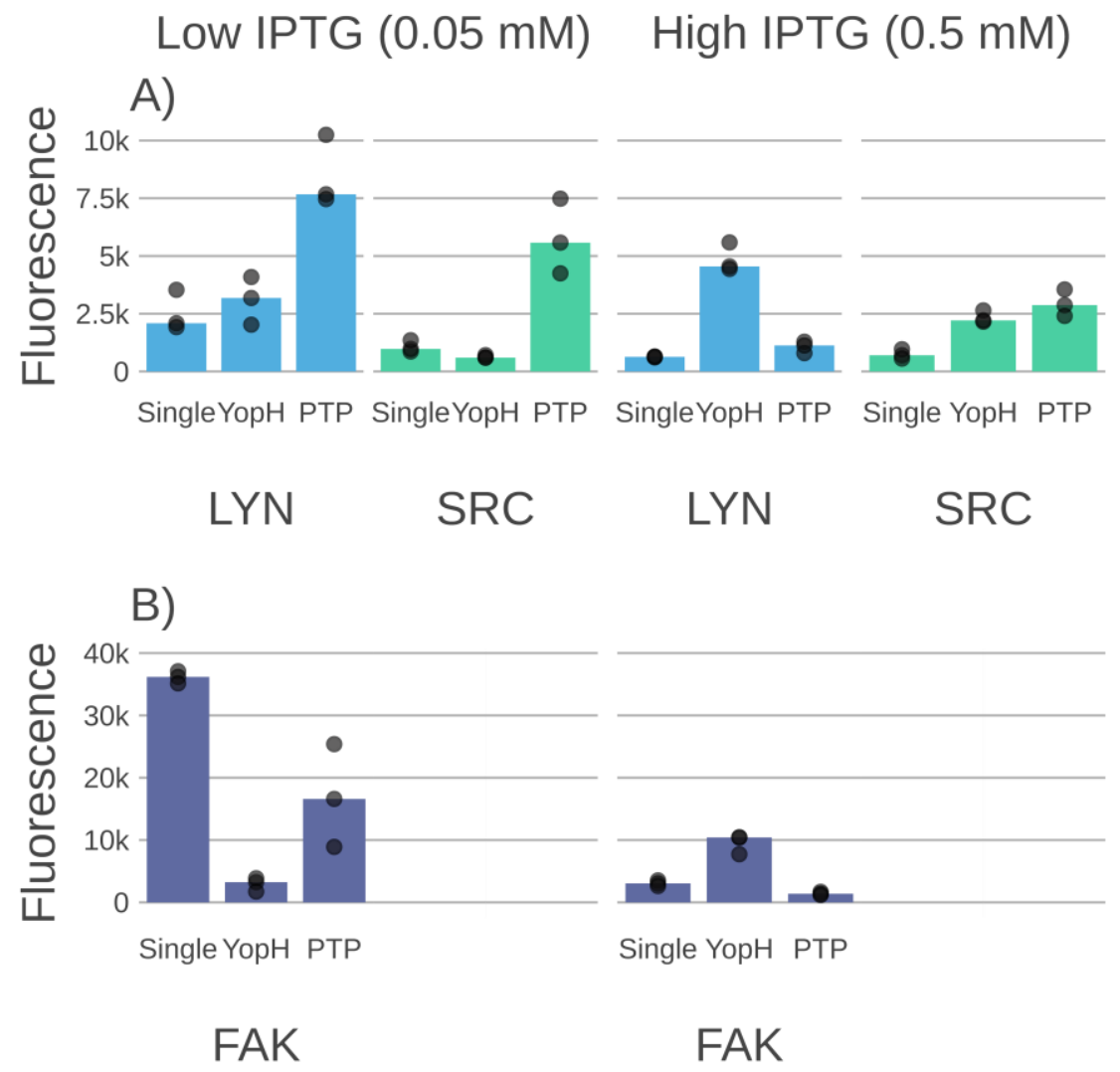

\section{Figure 4. Small-scale expression in Escherichia coli}

Protein expression was evaluated by fluorescence from the fused mCitrine tag. Bars indicate median of three measurements (shown as dots), each starting from a different bacterial colony. 'Single': expression of KD alone, without phosphatase. Fluorescence data were normalized to cell density. A) Low induction (IPTG $0.05 \mathrm{mM}$ ) and PTP1B co-transformation was the overall 
best condition. B) Expression of FAK KD-mCitrine showed high apparent expression which stemmed from a truncation product lacking the KD.

\begin{tabular}{|c|c|}
\hline A) After StrepTrap affinity purification \\
\hline Kinase sample & Yield $(\mathrm{mg})$ \\
\hline Single Lyn & 6.8 \\
\hline Single Src & 0.4 \\
\hline PTP1B Lyn & 3.7 \\
\hline PTP1B Src & 6.2 \\
\hline B) After size exclusion purification \\
\hline Kinase sample & Yield $(\mathrm{mg})$ \\
\hline Single Lyn & 0.1 \\
\hline Single Src & N.D. \\
\hline PTP1B Lyn & 0.1 \\
\hline PTP1B Src & 1.4 \\
\hline
\end{tabular}

Table 1. Protein yield after large-scale expression and purification.

Yield is presented per liter of culture. 'Single': expression of KD alone, without phosphatase

Influence of phosphatase co-expression

In agreement with previous reports, we were able to express Src KD (Albanese et al., 2018; Seeliger et al., 2005) and Lyn KD (Li et al., 2016; H. Chin et al., 1998) with and without phosphatase co-expression (Figure 4A). At high induction levels, YopH co-expression often performed better, but the overall best condition for both constructs was PTP1B co-expression at a low $(0.05 \mathrm{mM})$ IPTG concentration and low $\left(20{ }^{\circ} \mathrm{C}\right)$ temperature. These conditions (for comparison, with and without PTP1B co-expression) were then used for the purification of Src and Lyn KDs from 1L cultures.

In line with previous reports (Albanese et al., 2018; Cui \& Sun, 2018; Seeliger et al., 2005), phosphatase co-expression improved Src KD yield from $0.4 \mathrm{mg} / \mathrm{L}$ to $6.2 \mathrm{mg} / \mathrm{L}$ after affinity purification (Table 1A). By contrast, expression of Lyn KD alone performed two-fold better $(6.8 \mathrm{mg} / \mathrm{L})$ than its co-expression with PTP1B $(3.7 \mathrm{mg} / \mathrm{L})$. Phosphatase co-expression thus improved the primary yield of Src KD but not the yield of the highly similar Lyn KD. Although overall yields differed, all samples showed similar specific kinase activities after this initial stage of purification, regardless whether expressed alone or with a phosphatase (Figure 5A). However, after SEC, only samples from the PTP1B co-expression retained kinase activity (Figure 5B). Importantly, SEC reduced the final yield of Lyn KD and Src KD by $95 \%$ or $80 \%$, 
respectively (Table 1B), indicating that most of the affinity-purified fraction had formed soluble aggregates. This effect has been observed by others (Piserchio et al., 2012; Haacke et al., 2009), and illustrates the problem of correlating soluble protein quantity with active monomeric KD. In our case, the affinity purification yield was highest for Lyn KD but a milligram quantity of high quality and active protein could, eventually, only be obtained for Src KD. Although the primary yield of Lyn KD did not benefit from the presence of PTP1B, monomeric and active Lyn KD or Src KD could only be obtained from cultures co-expressing the phosphatase. This may indicate that the phosphatase is not only protecting the host from cytotoxic effects (for which there is no clear evidence in the case of Lyn) but can also protect the kinase from uncontrolled (auto)phosphorylation and misfolding or aggregation (Shrestha et al., 2012).

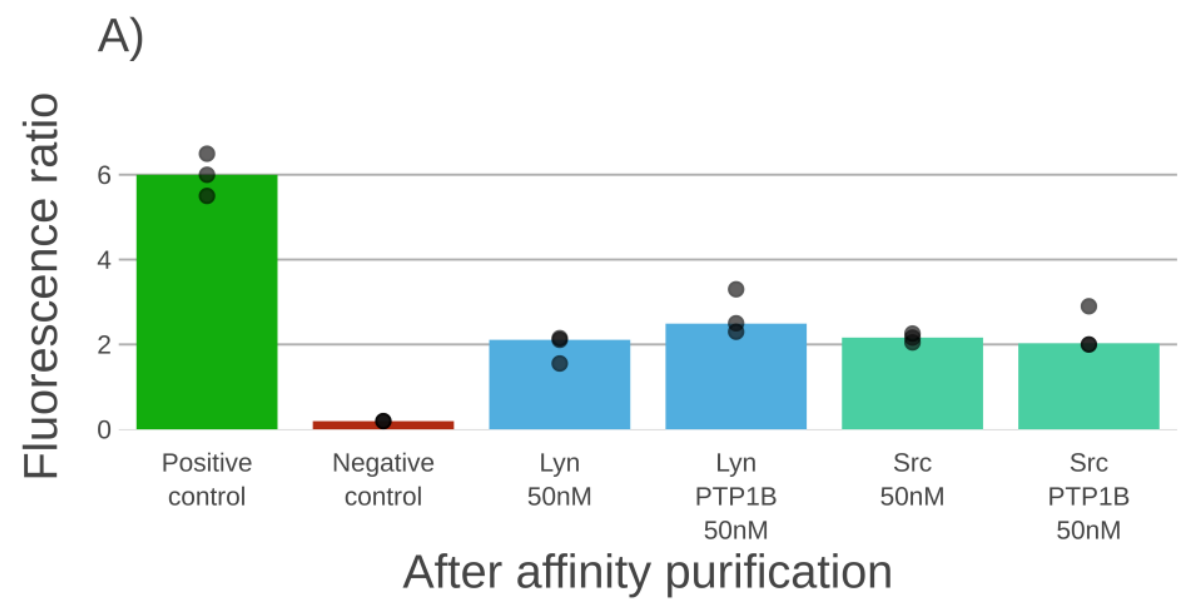

B)

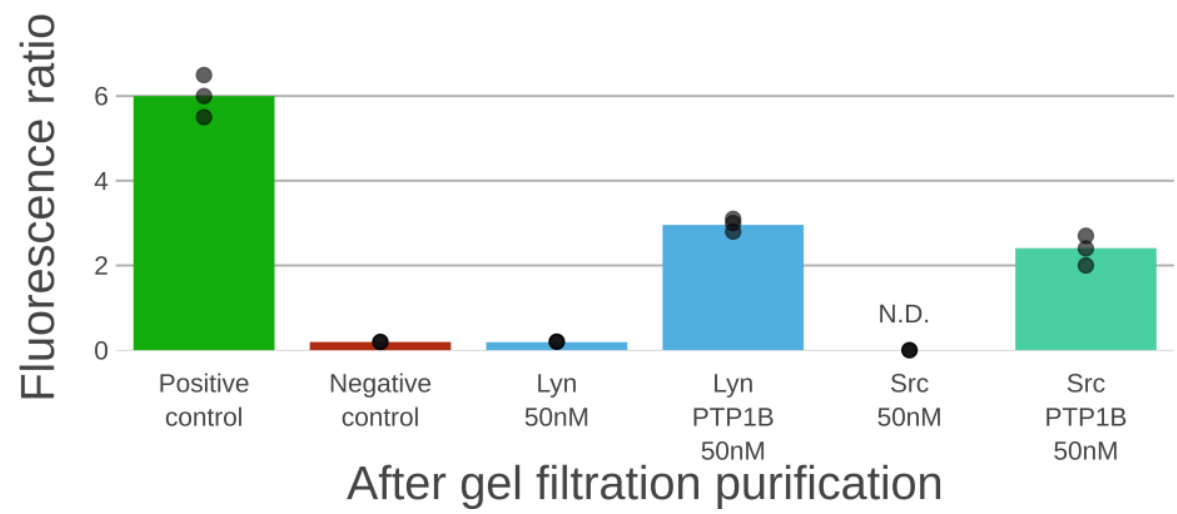

Figure 5. Kinase activity of E.coli expressed proteins.

Activity was measured with the Z'LYTE kinase assay. A high fluorescence ratio indicates high kinase activity. Positive control: signal obtained from the fully phosphorylated substrate peptide. A) Kinase activity of proteins (expressed alone or co-expressed with PTP1B) after affinity purification. B) Kinase activity after an additional SEC. N.D.: Owing to low yield, Src 
KD expressed alone was not further purified by SEC. Bars give the median of three measurements (represented by dots).

PTP1B co-expression and kinase assays

We noticed that phosphopeptide-positive controls from the commercial kinase assay were significantly dephosphorylated when exposed to protein samples originating from phosphatase co-expression cultures. This phosphatase activity could not be removed by filtration over a GST affinity column and, given that phosphatases have similar sizes as KDs, even persisted after SEC (Figure 6B). If undetected, phosphatase contamination would of course lead to a marked underestimation of kinase activity. It may or may not also be the reason for our observation that kinase assays worked best at lower kinase concentrations. We haven't explored this effect in detail but advise to test several concentrations when establishing the assay.

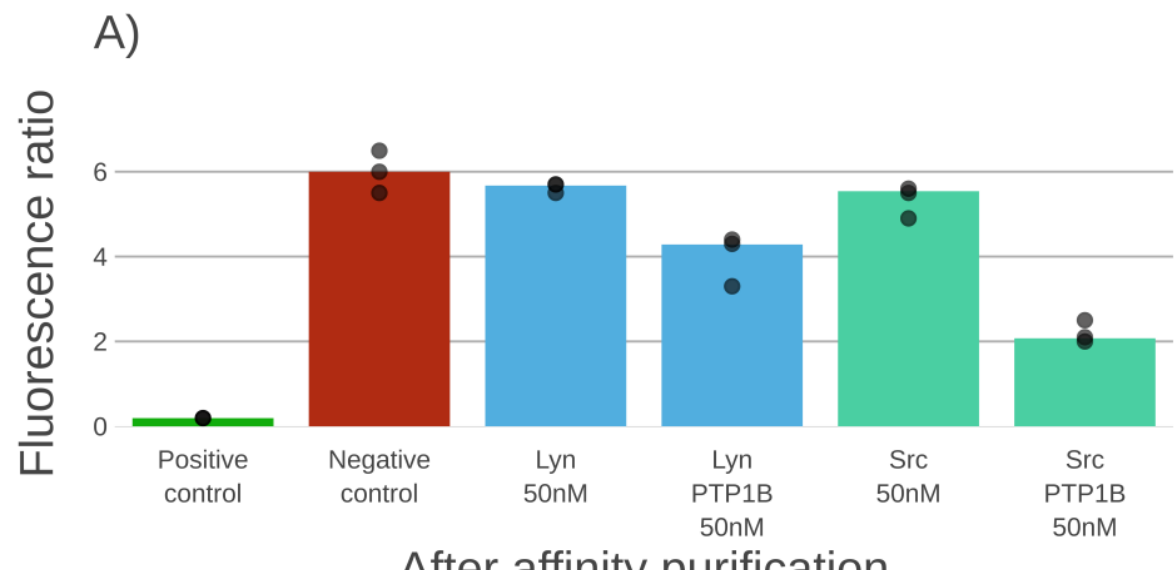

B)

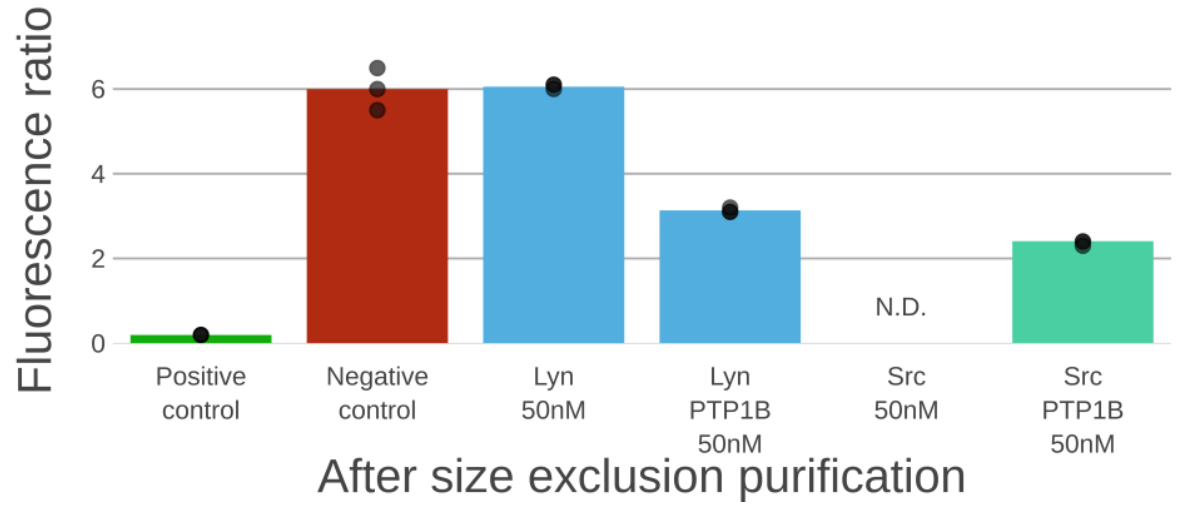

Figure 6. Phosphatase activity of $E$. coli expressed proteins. 
High values indicate low phosphatase activity. The negative control (fully phosphorylated peptide) defines the fluorescence ratio without phosphatase activity. PTP1B co-expressed samples show phosphatase activity. Bars give the median of three measurements (represented by dots).

\section{Conclusion}

Protein tyrosine kinases are of high scientific and therapeutic interest as anti-cancer drug targets. They, moreover, hold promise as regulatory building blocks in protein-based synthetic biology applications. Both traditional structural biology as well as such bioengineering efforts critically depend on rapid access to larger quantities of pure protein. Insect cell expression remains the most predictable and reliable option for the expression of PTK catalytic domains but is prohibitively slow and expensive for higher throughput experiments or repeated designbuild-test cycles.

Expression of PTKs from E. coli has been reported early on with varying success. Although the comparison is complicated by differences in sequence boundaries and fusion tags, which can have a marked impact (Albanese et al., 2018; Elkins, 2014; W. Wang et al., 2006), the literature record indicates two connected reasons for the difficulties associated with bacterial expression of many PTKs: (i) cytotoxicity of the unchecked tyrosine phosphorylation within a non-adapted organism, and (ii) the production of soluble or insoluble PTK aggregates due to misfolding. Misfolding may be caused by a lack of eukaryotic chaperons, by non-optimal domain boundaries, or it can result from the PTK's own unchecked (co-translational) autophosphorylation. Conveniently, phosphatase co-expression can simultaneously address both host cytotoxicity and autophosphorylation-induced misfolding, but may result in downstream phosphatase contamination that affects kinase activity.

Another common pitfall is the prevalence of truncation products or soluble aggregates, which may be both active or inactive. This effect complicates the interpretation of small-scale expression screening and one-step affinity purifications. Size-exclusion chromatography and kinase activity assays are highly recommended before embarking on further experiments. It is also worth exploring different solubility tags, protein boundaries or sequences from different species, which can all have a big impact on product quantity and quality, as even closely related kinase domains can behave very differently. Fast and affordable gene synthesis, codon optimization, modern cloning techniques and robotics now enable the rapid testing of different constructs and conditions, thus greatly facilitating successful E. coli production of PTKs. 


\section{Acknowledgements}

This research was supported by the King Abdullah University of Science and Technology (KAUST) through the baseline fund and the Award No. URF/1/2602-01 and FCC/1/1976-21 from the Office of Sponsored Research (OSR). Supplemental data, detailed methods and complete sequences are available on http://github.com/strubelab/kinaseexpress.

\section{References}

Agafonov, R. V., Wilson, C., Otten, R., Buosi, V., \& Kern, D. (2014). Energetic dissection of Gleevec's selectivity toward human tyrosine kinases. Nature Structural \& Molecular Biology, 21(10), 848-853. https://doi.org/10.1038/nsmb.2891

Albanese, S. K., Parton, D. L., Işık, M., Rodríguez-Laureano, L., Hanson, S. M., Behr, J. M., ... Chodera, J. D. (2018). An Open Library of Human Kinase Domain Constructs for Automated Bacterial Expression. Biochemistry, 57(31), 4675-4689. https://doi.org/10.1021/acs.biochem.7b01081

Alonso, A., Sasin, J., Bottini, N., Friedberg, I., Friedberg, I., Osterman, A., ... Mustelin, T. (2004). Protein tyrosine phosphatases in the human genome. Cell, 117(6), 699-711. https://doi.org/10.1016/j.cell.2004.05.018

Altıntop, M. D., Sever, B., Akalın Çiftçi, G., Turan-Zitouni, G., Kaplancıklı, Z. A., \& Özdemir, A. (2018). Design, synthesis, in vitro and in silico evaluation of a new series of oxadiazolebased anticancer agents as potential Akt and FAK inhibitors. European Journal of Medicinal Chemistry, 155, 905-924. https://doi.org/10.1016/j.ejmech.2018.06.049

Amanchy, R., Zhong, J., Hong, R., Kim, J. H., Gucek, M., Cole, R. N., ... Pandey, A. (2009). Identification of c-Src tyrosine kinase substrates in platelet-derived growth factor receptor signaling. Molecular Oncology, 3(5-6), 439-450. https://doi.org/10.1016/j.molonc.2009.07.001

Arni, S., Le, T. H. N., de Wijn, R., Garcia-Villegas, R., Dankers, M., Weder, W., \& Hillinger, S. (2017). Ex vivo multiplex profiling of protein tyrosine kinase activities in early stages of human lung adenocarcinoma. Oncotarget, 8(40), 68599-68613. https://doi.org/10.18632/oncotarget.19803

Bankston, A. N., Ku, L., \& Feng, Y. (2017). Active Cdk5 Immunoprecipitation and Kinase Assay. Bio-Protocol, 7(13). https://doi.org/10.21769/BioProtoc.2363

Beeler, J. F., LaRochelle, W. J., Chedid, M., Tronick, S. R., \& Aaronson, S. A. (1994). Prokaryotic expression cloning of a novel human tyrosine kinase. Molecular and Cellular Biology, 14(2), 982-988.

Bhoir, S., Shaik, A., Thiruvenkatam, V., \& Kirubakaran, S. (2018). High yield bacterial expression, purification and characterisation of bioactive Human Tousled-like Kinase 1B involved in cancer. Scientific Reports, 8(1), 4796. https://doi.org/10.1038/s41598-018-22744-5

Bhullar, K. S., Lagarón, N. O., McGowan, E. M., Parmar, I., Jha, A., Hubbard, B. P., \& Rupasinghe, H. P. V. (2018). Kinase-targeted cancer therapies: progress, challenges and future directions. Molecular Cancer, 17(1), 48. https://doi.org/10.1186/s12943-018-08042 
Bjorge, J. D., Pang, A., \& Fujita, D. J. (2000). Identification of protein-tyrosine phosphatase 1B as the major tyrosine phosphatase activity capable of dephosphorylating and activating c-Src in several human breast cancer cell lines. The Journal of Biological Chemistry, 275(52), 41439-41446. https://doi.org/10.1074/jbc.M004852200

Bliska, J. B., Guan, K. L., Dixon, J. E., \& Falkow, S. (1991). Tyrosine phosphate hydrolysis of host proteins by an essential Yersinia virulence determinant. Proceedings of the National Academy of Sciences of the United States of America, 88(4), 1187-1191.

Bougeret, C., Rothhut, B., Jullien, P., Fischer, S., \& Benarous, R. (1993). Recombinant Csk expressed in Escherichia coli is autophosphorylated on tyrosine residue(s). Oncogene, 8(5), 1241-1247.

Breen, M. E., \& Soellner, M. B. (2015). Small Molecule Substrate Phosphorylation Site Inhibitors of Protein Kinases: Approaches and Challenges. ACS Chemical Biology, 10(1), 175-189. https://doi.org/10.1021/cb5008376

Bruel, C., Cha, K., Reeves, P. J., Getmanova, E., \& Khorana, H. G. (2000). Rhodopsin kinase: Expression in mammalian cells and a two-step purification. Proceedings of the National Academy of Sciences of the United States of America, 97(7), 3004-3009.

Camacho-Soto, K., Castillo-Montoya, J., Tye, B., \& Ghosh, I. (2014). Ligand-Gated Split-Kinases. Journal of the American Chemical Society, 136(10), 3995-4002. https://doi.org/10.1021/ja4130803

Carazo, A., \& Pávek, P. (2015). The Use of the LanthaScreen TR-FRET CAR Coactivator Assay in the Characterization of Constitutive Androstane Receptor (CAR) Inverse Agonists. Sensors (Basel, Switzerland), 15(4), 9265-9276. https://doi.org/10.3390/s150409265

Carlson, C. B., Robers, M. B., Vogel, K. W., \& Machleidt, T. (2009). Development of LanthaScreen cellular assays for key components within the PI3K/AKT/mTOR pathway. Journal of Biomolecular Screening, 14(2), 121-132. https://doi.org/10.1177/1087057108328132

Chambers, S. P., Austen, D. A., Fulghum, J. R., \& Kim, W. M. (2004). High-throughput screening for soluble recombinant expressed kinases in Escherichia coli and insect cells. Protein Expression and Purification, 36(1), 40-47. https://doi.org/10.1016/j.pep.2004.03.003

Chin, H., Arai, A., Wakao, H., Kamiyama, R., Miyasaka, N., \& Miura, O. (1998). Lyn Physically Associates With the Erythropoietin Receptor and May Play a Role in Activation of the Stat5 Pathway. Blood, 91(10), 3734-3745.

Chin, J. X., Chung, B. K.-S., \& Lee, D.-Y. (2014). Codon Optimization OnLine (COOL): a webbased multi-objective optimization platform for synthetic gene design. Bioinformatics, 30(15), 2210-2212. https://doi.org/10.1093/bioinformatics/btu192

Correa, A., \& Oppezzo, P. (2015). Overcoming the Solubility Problem in E. coli: Available Approaches for Recombinant Protein Production. In E. García-Fruitós (Ed.), Insoluble Proteins: Methods and Protocols (pp. 27-44). New York, NY: Springer New York. https://doi.org/10.1007/978-1-4939-2205-5_2

Cui, Y., \& Sun, G. (2018). Structural versatility that serves the function of the HRD motif in the catalytic loop of protein tyrosine kinase, Src. Protein Science, O(ja). https://doi.org/10.1002/pro.3554

Deng, Y., Alicea-Velázquez, N. L., Bannwarth, L., Lehtonen, S. I., Boggon, T. J., Cheng, H.-C., ... Turk, B. E. (2014). Global Analysis of Human Nonreceptor Tyrosine Kinase Specificity 
Using High-Density Peptide Microarrays. Journal of Proteome Research, 13(10), 43394346. https://doi.org/10.1021/pr500503q

Diaz, J. E., Morgan, C. W., Minogue, C. E., Hebert, A. S., Coon, J. J., \& Wells, J. A. (2017). A Split-Abl Kinase for Direct Activation in Cells. Cell Chemical Biology. https://doi.org/10.1016/j.chembiol.2017.08.007

Du, P., Loulakis, P., Luo, C., Mistry, A., Simons, S. P., LeMotte, P. K., ... Xie, Z. (2005). Phosphorylation of serine residues in histidine-tag sequences attached to recombinant protein kinases: A cause of heterogeneity in mass and complications in function. Protein Expression and Purification, 44(2), 121-129. https://doi.org/10.1016/j.pep.2005.04.018

Dussaq, A., Anderson, J. C., Willey, C. D., \& Almeida, J. S. (2016). Mechanistic Parameterization of the Kinomic Signal in Peptide Arrays. Journal of Proteomics \& Bioinformatics, 9(5), 151-157. https://doi.org/10.4172/jpb.1000401

Elegheert, J., Behiels, E., Bishop, B., Scott, S., Woolley, R. E., Griffiths, S. C., ... Aricescu, A. R. (2018). Lentiviral transduction of mammalian cells for fast, scalable and high-level production of soluble and membrane proteins. Nature Protocols, 13(12), 2991-3017. https://doi.org/10.1038/s41596-018-0075-9

Elkins, J. M. (2014). Case Study-Structural Genomics and Human Protein Kinases. In W. F. Anderson (Ed.), Structural Genomics and Drug Discovery: Methods and Protocols (pp. 325-336). New York, NY: Springer New York. https://doi.org/10.1007/978-1-4939-03542_24

Fan, G., Lin, G., Lucito, R., \& Tonks, N. K. (2013). Protein-tyrosine Phosphatase 1B Antagonized Signaling by Insulin-like Growth Factor-1 Receptor and Kinase BRK/PTK6 in Ovarian Cancer Cells. Journal of Biological Chemistry, 288(34), 24923-24934. https://doi.org/10.1074/jbc.M113.482737

Filippakopoulos, P., Kofler, M., Hantschel, O., Gish, G. D., Grebien, F., Salah, E., ... Knapp, S. (2008). Structural Coupling of SH2-Kinase Domains Links Fes and Abl Substrate Recognition and Kinase Activation. Cell, 134(5), 793-803. https://doi.org/10.1016/j.cell.2008.07.047

Fountas, A., Diamantopoulos, L.-N., \& Tsatsoulis, A. (2015). Tyrosine Kinase Inhibitors and Diabetes: A Novel Treatment Paradigm? Trends in Endocrinology and Metabolism: TEM, 26(11), 643-656. https://doi.org/10.1016/j.tem.2015.09.003

Garcia, P., Shoelson, S. E., George, S. T., Hinds, D. A., Goldberg, A. R., \& Miller, W. T. (1993). Phosphorylation of synthetic peptides containing Tyr-Met-X-Met motifs by nonreceptor tyrosine kinases in vitro. Journal of Biological Chemistry, 268(33), 25146-25151.

Glickman, J. F. (2004). Assay Development for Protein Kinase Enzymes. In G. S. Sittampalam, N. P. Coussens, K. Brimacombe, A. Grossman, M. Arkin, D. Auld, ... X. Xu (Eds.), Assay Guidance Manual. Bethesda (MD): Eli Lilly \& Company and the National Center for Advancing Translational Sciences. Retrieved from http://www.ncbi.nlm.nih.gov/books/NBK91991/

Goehring, A., Lee, C.-H., Wang, K. H., Michel, J. C., Claxton, D. P., Baconguis, I., ... Gouaux, E. (2014). Screening and large-scale expression of membrane proteins in mammalian cells for structural studies. Nature Protocols, 9(11), 2574-2585. https://doi.org/10.1038/nprot.2014.173 
Gong, X., Ji, J., Xie, J., Zhou, Y., Zhang, J., \& Zhong, W. (2006). Expression, purification, and bioactivity of GST-fused v-Src from a bacterial expression system. Journal of Zhejiang University. Science. B, 7(1), 13-19. https://doi.org/10.1631/jzus.2006.B0013

Gopinathan, U., Redalen, K. R., Trøseid, A.-M., Kierulf, P., Brandtzaeg, P., Ree, A. H., ... $\emptyset v s t e b \varnothing$, R. (2018). Large-scale reduction of tyrosine kinase activities in human monocytes stimulated in vitro with N. meningitidis. PloS One, 13(1), e0181912. https://doi.org/10.1371/journal.pone.0181912

Gordley, R. M., Bugaj, L. J., \& Lim, W. A. (2016). Modular engineering of cellular signaling proteins and networks. Current Opinion in Structural Biology, 39, 106-114. https://doi.org/10.1016/j.sbi.2016.06.012

Griesbeck, O., Baird, G. S., Campbell, R. E., Zacharias, D. A., \& Tsien, R. Y. (2001). Reducing the environmental sensitivity of yellow fluorescent protein. Mechanism and applications. The Journal of Biological Chemistry, 276(31), 29188-29194. https://doi.org/10.1074/jbc.M102815200

Grünberg, R., \& Serrano, L. (2010). Strategies for protein synthetic biology. Nucleic Acids Research, 38(8), 2663-2675. https://doi.org/10.1093/nar/gkq139

Haacke, A., Fendrich, G., Ramage, P., \& Geiser, M. (2009). Chaperone over-expression in Escherichia coli: Apparent increased yields of soluble recombinant protein kinases are due mainly to soluble aggregates. Protein Expression and Purification, 64(2), 185-193. https://doi.org/10.1016/j.pep.2008.10.022

Hawes, B. E., \& Biesen, T. van. (1999). Protein Tyrosine Kinase Activity Assays. Current Protocols in Pharmacology, $\quad$ 5(1), https://doi.org/10.1002/0471141755.ph0305s05

Hofmann, C., Sandig, V., Jennings, G., Rudolph, M., Schlag, P., \& Strauss, M. (1995). Efficient gene transfer into human hepatocytes by baculovirus vectors. Proceedings of the National Academy of Sciences of the United States of America, 92(22), 10099-10103.

Hunter, T. (2009). Tyrosine phosphorylation: thirty years and counting. Current Opinion in Cell Biology, 21(2), 140-146. https://doi.org/10.1016/j.ceb.2009.01.028

Karra, A. S., Stippec, S., \& Cobb, M. H. (2017). Assaying Protein Kinase Activity with Radiolabeled ATP. Journal of Visualized Experiments : JoVE, (123). https://doi.org/10.3791/55504

Kemble, D. J., Wang, Y.-H., \& Sun, G. (2006). Bacterial expression and characterization of catalytic loop mutants of SRC protein tyrosine kinase. Biochemistry, 45(49), 14749-14754. https://doi.org/10.1021/bi061664+

Khan, K. H. (2013). Gene Expression in Mammalian Cells and its Applications. Advanced Pharmaceutical Bulletin, 3(2), 257-263. https://doi.org/10.5681/apb.2013.042

Kimple, M. E., Brill, A. L., \& Pasker, R. L. (2013). Overview of Affinity Tags for Protein Purification. Current Protocols in Protein Science / Editorial Board, John E. Coligan ... [et Al.], 73, Unit-9.9. https://doi.org/10.1002/0471140864.ps0909s73

Labots, M., Gotink, K. J., Dekker, H., Azijli, K., van der Mijn, J. C., Huijts, C. M., ... Verheul, H. M. W. (2016). Evaluation of a tyrosine kinase peptide microarray for tyrosine kinase inhibitor therapy selection in cancer. Experimental \& Molecular Medicine, 48(12), e279. https://doi.org/10.1038/emm.2016.114 
Lawrence, D. S., \& Wang, Q. (2007). Seeing Is Believing: Peptide-Based Fluorescent Sensors of Protein Tyrosine Kinase Activity. Chembiochem: A European Journal of Chemical Biology, 8(4), 373-378. https://doi.org/10.1002/cbic.200600473

Li, X., He, S., Zhou, X., Ye, Y., Tan, S., Zhang, S., ... Wu, M. (2016). Lyn Delivers Bacteria to Lysosomes for Eradication through TLR2-Initiated Autophagy Related Phagocytosis. PLOS Pathogens, 12(1), e1005363. https://doi.org/10.1371/journal.ppat.1005363

Lim, W. A., \& Pawson, T. (2010). Phosphotyrosine Signaling: Evolving a New Cellular Communication System. Cell, 142(5), 661-667. https://doi.org/10.1016/j.cell.2010.08.023

Liu, M., Poulose, S., Schuman, E., Zaitsev, A. D., Dobson, B., Auerbach, K., ... Yue, Z. (2010). Development of a mechanism-based high-throughput screen assay for leucine-rich repeat kinase 2--discovery of LRRK2 inhibitors. Analytical Biochemistry, 404(2), 186-192. https://doi.org/10.1016/j.ab.2010.05.033

Lorenz, U. (2011). Protein Tyrosine Phosphatase Assays. Current Protocols in Immunology / Edited by John E. Coligan ... [et Al.], CHAPTER, Unit-11.7. https://doi.org/10.1002/0471142735.im1107s93

Luckow, V. A., Lee, S. C., Barry, G. F., \& Olins, P. O. (1993). Efficient generation of infectious recombinant baculoviruses by site-specific transposon-mediated insertion of foreign genes into a baculovirus genome propagated in Escherichia coli. Journal of Virology, 67(8), 4566-4579.

Ma, H., Deacon, S., \& Horiuchi, K. (2008). The challenge of selecting protein kinase assays for lead discovery optimization. Expert Opinion on Drug Discovery, 3(6), 607-621. https://doi.org/10.1517/17460441.3.6.607

Ma, Y., Nagamune, T., \& Kawahara, M. (2014). Split focal adhesion kinase for probing proteinprotein interactions. Biochemical Engineering Journal, 90, 272-278. https://doi.org/10.1016/j.bej.2014.06.022

Marholz, L. J., Zeringo, N. A., Lou, H. J., Turk, B. E., \& Parker, L. L. (2018). In Silico Design and in Vitro Characterization of Universal Tyrosine Kinase Peptide Substrates. Biochemistry, 57(12), 1847-1851. https://doi.org/10.1021/acs.biochem.8b00044

Marin, V., Groveman, B. R., Qiao, H., Xu, J., Ali, M. K., Fang, X.-Q., ... Yu, X.-M. (2010). CHARACTERIZATION OF NEURONAL SRC KINASE PURIFIED FROM A BACTERIAL EXPRESSION SYSTEM. Protein Expression and Purification, 74(2), 289297. https://doi.org/10.1016/j.pep.2010.06.004

Mazet, F., Dunster, J. L., Jones, C. I., Vaiyapuri, S., Tindall, M. J., Fry, M. J., \& Gibbins, J. M. (2015). A high-density immunoblotting methodology for quantification of total protein levels and phosphorylation modifications. Scientific Reports, 5, 16995. https://doi.org/10.1038/srep16995

Mutalik, V. K., Guimaraes, J. C., Cambray, G., Lam, C., Christoffersen, M. J., Mai, Q.-A., ... Endy, D. (2013). Precise and reliable gene expression via standard transcription and translation initiation elements. Nature Methods, 10(4), 354-360. https://doi.org/10.1038/nmeth.2404

Nettleship, J. E., Assenberg, R., Diprose, J. M., Rahman-Huq, N., \& Owens, R. J. (2010). Recent advances in the production of proteins in insect and mammalian cells for structural biology. Journal of Structural Biology, 172(1), 55-65. https://doi.org/10.1016/j.jsb.2010.02.006 
Newman, M., \& Josiah, S. (2004). Utilization of fluorescence polarization and time resolved fluorescence resonance energy transfer assay formats for SAR studies: Src kinase as a model system. Journal of Biomolecular Screening, 9(6), 525-532. https://doi.org/10.1177/1087057104264597

Osusky, M., Taylor, S. J., \& Shalloway, D. (1995). Autophosphorylation of Purified c-Src at its Primary Negative Regulation Site. Journal of Biological Chemistry, 270(43), 2572925732. https://doi.org/10.1074/jbc.270.43.25729

Patterson, H., Nibbs, R., McInnes, I., \& Siebert, S. (2014). Protein kinase inhibitors in the treatment of inflammatory and autoimmune diseases. Clinical and Experimental Immunology, 176(1), 1-10. https://doi.org/10.1111/cei.12248

Pawson, T. (1995). Protein modules and signalling networks. Nature, 373(6515), 573-580. https://doi.org/10.1038/373573a0

Pijlman, G. P., van Schijndel, J. E., \& Vlak, J. M. (2003). Spontaneous excision of BAC vector sequences from bacmid-derived baculovirus expression vectors upon passage in insect cells. The Journal of General Virology, 84(Pt 10), 2669-2678. https://doi.org/10.1099/vir.0.19438-0

Piserchio, A., Cowburn, D., \& Ghose, R. (2012). Expression and Purification of Src-family Kinases for Solution NMR Studies. Methods in Molecular Biology (Clifton, N.J.), 831, 111-131. https://doi.org/10.1007/978-1-61779-480-3_7

SGC. (2013, November 5). Progress in protein kinase structural biology. Retrieved November 28, 2018, from https://www.thesgc.org/scientists/resources/kinases

Rodems, S. M., Hamman, B. D., Lin, C., Zhao, J., Shah, S., Heidary, D., ... Pollok, B. A. (2002). A FRET-Based Assay Platform for Ultra-High Density Drug Screening of Protein Kinases and Phosphatases. ASSAY and Drug Development Technologies, 1(1), 9-19. https://doi.org/10.1089/154065802761001266

Rosano, G. L., \& Ceccarelli, E. A. (2014). Recombinant protein expression in Escherichia coli: advances and challenges. Frontiers in Microbiology, 5. https://doi.org/10.3389/fmicb.2014.00172

Sacco, F., Perfetto, L., Castagnoli, L., \& Cesareni, G. (2012). The human phosphatase interactome: An intricate family portrait. Febs Letters, 586(17), 2732-2739. https://doi.org/10.1016/j.febslet.2012.05.008

Saya, H., Lee, P. S., Nishi, T., Izawa, I., Nakajima, M., Gallick, G. E., \& Levin, V. A. (1993). Bacterial expression of an active tyrosine kinase from a protein $\mathrm{A} /$ truncated $\mathrm{c}$-src fusion protein. FEBS Letters, 327(2), 224-230.

Schmidt, T. G. M., Batz, L., Bonet, L., Carl, U., Holzapfel, G., Kiem, K., ... Stanar, K. (2013). Development of the Twin-Strep-tag® and its application for purification of recombinant proteins from cell culture supernatants. Protein Expression and Purification, 92(1), 54-61. https://doi.org/10.1016/j.pep.2013.08.021

Seeliger, M. A., Young, M., Henderson, M. N., Pellicena, P., King, D. S., Falick, A. M., \& Kuriyan, J. (2005). High yield bacterial expression of active c-Abl and c-Src tyrosine kinases. Protein Science: A Publication of the Protein Society, 14(12), 3135-3139. https://doi.org/10.1110/ps.051750905

Sharma, K., D’Souza, R. C. J., Tyanova, S., Schaab, C., Wiśniewski, J. R., Cox, J., \& Mann, M. (2014). Ultradeep Human Phosphoproteome Reveals a Distinct Regulatory Nature of Tyr 
and Ser/Thr-Based Signaling. Cell Reports, 8(5), 1583-1594. https://doi.org/10.1016/j.celrep.2014.07.036

Shrestha, A., Hamilton, G., O’Neill, E., Knapp, S., \& Elkins, J. M. (2012). Analysis of conditions affecting auto-phosphorylation of human kinases during expression in bacteria. Protein Expression and Purification, 81(1), 136-143. https://doi.org/10.1016/j.pep.2011.09.012

Smith, G. E., Summers, M. D., \& Fraser, M. J. (1983). Production of human beta interferon in insect cells infected with a baculovirus expression vector. Molecular and Cellular Biology, $3(12), 2156-2165$.

Sumaoka, J., Akiba, H., \& Komiyama, M. (2016). Selective Sensing of Tyrosine Phosphorylation in Peptides Using Terbium(III) Complexes. International Journal of Analytical Chemistry, 2016, 3216523. https://doi.org/10.1155/2016/3216523

Taipale, M., Krykbaeva, I., Koeva, M., Kayatekin, C., Westover, K. D., Karras, G. I., \& Lindquist, S. (2012). Quantitative Analysis of Hsp90-Client Interactions Reveals Principles of Substrate Recognition. Cell, 150(5), 987-1001. https://doi.org/10.1016/j.cell.2012.06.047

Thomas, J. G., Ayling, A., \& Baneyx, F. (1997). Molecular chaperones, folding catalysts, and the recovery of active recombinant proteins fromE. coli. Applied Biochemistry and Biotechnology, 66(3), 197-238. https://doi.org/10.1007/BF02785589

Tu, P. N., Wang, Y., Cai, M., Zhou, X., \& Zhang, Y. (2014). Co-expression of protein tyrosine kinases EGFR-2 and PDGFR $\beta$ with protein tyrosine phosphatase 1B in Pichia pastoris. Journal of Microbiology and Biotechnology, 24(2), 152-159.

Utepbergenov, D., Hennig, P. M., Derewenda, U., Artamonov, M. V., Somlyo, A. V., \& Derewenda, Z. S. (2016). Bacterial Expression, Purification and In Vitro Phosphorylation of Full-Length Ribosomal S6 Kinase 2 (RSK2). PLoS ONE, 11(10). https://doi.org/10.1371/journal.pone.0164343

van Oers, M. M., Pijlman, G. P., \& Vlak, J. M. (2015). Thirty years of baculovirus-insect cell protein expression: from dark horse to mainstream technology. The Journal of General Virology, 96(Pt 1), 6-23. https://doi.org/10.1099/vir.0.067108-0

Verba, K. A., Wang, R. Y.-R., Arakawa, A., Liu, Y., Shirouzu, M., Yokoyama, S., \& Agard, D. A. (2016). Atomic structure of Hsp90-Cdc37-Cdk4 reveals that Hsp90 traps and stabilizes an unfolded kinase. Science (New York, N.Y.), 352(6293), 1542-1547. https://doi.org/10.1126/science.aaf5023

Vincent, C., Doublet, P., Grangeasse, C., Vaganay, E., Cozzone, A. J., \& Duclos, B. (1999). Cells of Escherichia coli Contain a Protein-Tyrosine Kinase, Wzc, and a PhosphotyrosineProtein Phosphatase, Wzb. Journal of Bacteriology, 181(11), 3472-3477.

Wang, W., Marimuthu, A., Tsai, J., Kumar, A., Krupka, H. I., Zhang, C., ... West, B. L. (2006). Structural characterization of autoinhibited c-Met kinase produced by coexpression in bacteria with phosphatase. Proceedings of the National Academy of Sciences of the United States of America, 103(10), 3563-3568. https://doi.org/10.1073/pnas.0600048103

Wang, Y.-H., Ayrapetov, M. K., Lin, X., \& Sun, G. (2006). A new strategy to produce active human Src from bacteria for biochemical study of its regulation. Biochemical and Biophysical Research Communications, 346(2), 606-611. https://doi.org/10.1016/j.bbrc.2006.05.180

Weijland, A., Neubauer, G., Courtneidge, S. A., Mann, M., Wierenga, R. K., \& Superti-Furga, G. (1996). The purification and characterization of the catalytic domain of Src expressed in 
Schizosaccharomyces pombe. Comparison of unphosphorylated and tyrosine phosphorylated species. European Journal of Biochemistry, 240(3), 756-764.

Wilson, C., Agafonov, R. V., Hoemberger, M., Kutter, S., Zorba, A., Halpin, J., ... Kern, D. (2015). Using ancient protein kinases to unravel a modern cancer drug's mechanism. Science, 347(6224), 882-886. https://doi.org/10.1126/science.aaa1823

Wu, P., Nielsen, T. E., \& Clausen, M. H. (2016). Small-molecule kinase inhibitors: an analysis of FDA-approved drugs. Drug Discovery Today, 21(1), 5-10. https://doi.org/10.1016/j.drudis.2015.07.008 